\title{
Enhancing Early Mobility With a Speaking Valve
}

Early mobility is a safe, cost-effective method used to assist in patients' liberation from intensive care. ${ }^{1,2}$ Concerns have been raised about the cost associated with early mobilization programs. Despite good results in some studies, safety concerns remain a key element for mobilizing patients while receiving mechanical ventilation. ${ }^{3}$ Early mobilization does not just mean walking. Other tools used to actively mobilize patients include in-bed cycling, dangling from the bed, standing, and bedside transfers from bed to a chair. ${ }^{1}$ Safety concerns not withstanding, early active mobilization is used routinely in patients who are vulnerable to adverse outcomes associated with mechanical ventilation. In the absence of early mobilization, patients are further prone to ICU-acquired weakness and functional disability. ${ }^{3}$ Fatigue, weakness, and decreased functional status are known to last up to 1 year in ICU survivors. Early mobility is associated with decreased ICU length of stay, decreased hospital length of stay, decreased hospital readmissions, and, importantly, increased ventilator-free days. ${ }^{4}$ Current guidelines for early mobility state that intubation, including tracheostomy, does not preclude patients from being mobilized. ${ }^{5}$

When patients are tracheostomized in the ICU, they may experience a variety of benefits. One of the important reported benefits is an increase in ventilator-free days. ${ }^{6}$ Speaking valves are used to assist patients being weaned from mechanical ventilation to communicate more effectively after tracheostomy. Devices are available that can be used in-line with the ventilator as well as after ventilator liberation with a T-piece or tracheostomy collar. ${ }^{7}$ Once ventilator liberation is achieved, speaking valves provide patients with the ability to communicate, swallow, and improve diaphragmatic strength, which lengthens the periods of time that patients remain free from ventilator assistance, which ultimately leads to decannulation. ${ }^{7}$

When considered separately, early mobility and speaking valves may seem unrelated in the care of patients who are critically ill; however, both provide value in decreasing adverse outcomes and improving patients' overall experience. ${ }^{1,7}$ In this issue of ResPiRATORY CARE,

\footnotetext{
Correspondence: Karsten J Roberts MSc RRT, Department of Respiratory Care Services, Hospital of the University of Pennsylvania, 3400 Spruce Street, Ground Floor, Founders Building, Philadelphia, PA 19104; E-mail: karsten.j.roberts@gmail.com.
}

DOI: $10.4187 /$ respcare.07671
Ceron et $\mathrm{al}^{8}$ investigated a unique approach to assist patients who had tracheostomy with improved early mobility. This Brazilian study included 18 subjects observed as a prospective cohort. Subjects were included after tolerating a speaking valve for at least $30 \mathrm{~min}$. Forty-five other patients were excluded from the study due to language and cognitive difficulties as well as 7 patients who were undergoing palliative care. ${ }^{8}$

\section{See the Original Study on Page 144}

The Perme ICU mobility score is a tool developed to quickly assess patients' ability to mobilize while critically ill. ${ }^{9}$ This system of measuring patients' mobility uses the ability to follow commands, functional strength, and endurance (measured in 2-min walk distance) to give patients a score from 0 to 32 . The score is derived from the physical therapist's assessment of mental status, barriers to mobility, strength, in-bed mobility, ability to transfer, gait, and endurance. The criteria used are meant to reflect the degree of critical illness exhibited by patients. Therefore, pain, ventilatory status, and progressive mobility as well as head and neck control are all considered when scoring an individual. Each criterion is given a maximum score, between 3 and 9 , depending on the area being assessed, for a maximum total of 32 points. On the low end of the scale, patients require more assistance, whereas a higher Perme score indicates a patient's need for less support. ${ }^{9}$

After one day of using the speaking valve in conjunction with active early mobilization, the median Perme score increased from median and range, 11.3 (10.1-12.0) to $18.2(16.2-20.1), P=.01 .^{8}$ Changes to the Perme score after day 1 of mobility carried no statistical significance. Categorically, the subjects' ability to transfer from one position (eg, transfer from bed to chair) represented the biggest changes in the Perme score within this cohort. ${ }^{8}$ One explanation for the improvement in mobility scores may be due to decreased work of breathing. Sutt et $\mathrm{al}^{10}$ demonstrated that speaking valves helped decrease work of breathing, in part, due to observed increases in end-expiratory lung volume.

The novelty of this methodology is intriguing. The authors state that this is the first study of its kind to combine early mobility with a speaking valve to improve 
mobility scores. ${ }^{8}$ Beyond this fact, the study results in a proof of concept due to both design and the small number of participants. Weaknesses include the fact that the authors did not validate the Perme score for subjects who had a tracheostomy. In addition, the Perme scores were assessed as totals and categories within the overall score were not evaluated for improvements within the categories. ${ }^{8}$ For example, the authors may have found improved benefit within the specific Perme score categories, such as in-bed mobility versus transfers, or vice versa, had they analyzed these more-specific data.

Despite the shortcomings of this study, the potential for more research in this niche is significant. Future research should include both longer observational studies as well as controlled groups of subjects. Because speaking valves add end-expiratory lung volume in the similar manner as PEEP,${ }^{10}$ future studies may compare Perme scores in patients receiving PEEP versus speaking valves during mobilization. Secondary outcomes such as ICU length of stay, hospital length of stay, and readmissions should be considered to further validate the methodology. Studies that combine the use of speaking valves with early mobilization could potentially show cost-effectiveness and improved outcomes.

Karsten J Roberts Department of Respiratory Care Services Hospital of the University of Pennsylvania Philadelphia, Pennsylvania

\section{REFERENCES}

1. Adler J, Malone D. Early mobilization in the intensive care unit: a systematic review. Cardiopulm Phys Ther J 2012;23(1):5-13.

2. Hunter A, Johnson L, Coustasse A. Reduction of intensive care unit length of stay: the case for early mobilization. Health Care Manag (Frederick) 2014;33(2):128-135.

3. Schmidt UH, Knecht L, MacIntyre NR. Should early mobilization be routine in mechanically ventilated patients? Respir Care 2016;61(6): $867-875$.

4. Schweickert WD, Pohlman MC, Pohlman AS, Nigos C, Pawlik AJ, Esbrook CL, et al. Early physical and occupational therapy in mechanically ventilated, critically ill patients: a randomised controlled trial. Lancet 2009;373(9678):1874-1882.

5. Hodgson CL, Stiller K, Needham DM, Tipping CJ, Harrold M, Baldwin $\mathrm{CE}$, et al. Expert consensus and recommendations on safety criteria for active mobilization of mechanically ventilated critically ill adults. Crit Care 2014;18(6):658.

6. Cheung NH, Napolitano LM. Tracheostomy: epidemiology, indications, timing, technique, and outcomes. Respir Care 2014;59(6):895915.

7. Hess DR, Altobelli NP. Tracheostomy tubes. Respir Care 2014;59 (6):956-971; discussion 971-973.

8. Ceron C, Otto D, Signorini AV, Beck MC, Camilis M, Sganzerla D, et al. The effect of speaking valves on ICU mobility of individuals with tracheostomy. Respir Care 2020;65(2):144-149.

9. Perme C, Nawa RK, Winkelman C, Masud F. A tool to assess mobility status in critically ill patients: the Perme Intensive Care Unit Mobility Score. Methodist DeBakey Cardiovasc J 2014;10(1):41-49.

10. Sutt AL, Caruana LR, Dunster KR, Cornwell PL, Anstey CM, Fraser JF. Speaking valves in tracheostomised ICU patients weaning off mechanical ventilation-do they facilitate lung recruitment? Crit Care 2016;20(1):91. 